\title{
Cultivating Leadership Development: A Comprehensive Program for Undergraduates
}

\author{
Justin P. Greenleaf \\ Assistant Professor, Department of Leadership Studies \\ Fort Hays State University
}

Kaley Klaus

Director of Student Leadership Development and Assessment, Department of Leadership Studies Fort Hays State University

Jill Arensdorf

Associate Professor, Department of Leadership Studies

Fort Hays State University

\begin{abstract}
The Voss Advanced Undergraduate Leadership Experience (VALUE), is a student cohort program with a competitive application process. Students must have a prerequisite level of leadership education and self-select into one of three designated tracks. Students are paired with faculty and community mentors to learn about operations and collaboration in today's organizations. The program culminates with students developing an e-Portfolio, which is evaluated to measure student learning outcomes.
\end{abstract}

\section{Introduction}

In an effort to improve and enhance the knowledge, skills, and attitudes of undergraduate students, the Department of Leadership Studies has developed the Voss Advanced Leadership Undergraduate Experience (VALUE) at Fort Hays State University. As part of this program, high-performing students participate in an intense year-long curricular experience that is above and beyond their traditional academic leadership coursework. The focus of the program is on demonstrating the capacity to move beyond simple academic understanding of leadership concepts, and to collaboratively make things happen in real world situations. In a world that is increasingly complex and interconnected, the students impacted by this program have the knowledge, skills, and attitudes needed to operate in this challenging new environment, and the conviction to accomplish change that can improve their organizations and society.

\section{Review of Related Literature}

In recent years, employers have expressed dissatisfaction with college graduates due to underdeveloped skills such as teamwork, communication, and problem-solving (Franz, 2008), particularly the ability to work effectively with others (Jackson, Sibson, \& Riebe, 2013). The 
ability to work in a team structure, or collaborating with others, is considered one of the most important skills employers look for when hiring college graduates behind holding a leadership position (NACE, 2014). Collaboration, "working with others in a common effort, sharing responsibility, authority, and accountability" (Wagner, 2006, p. 6), is also considered essential to effective leadership, along with attributes such as problem-solving skills, critical thinking skills, and effective communication skills; however, what is taught in the classroom is not always sufficient in developing these attributes within students (Astin \& Astin, 2000). To this end, scholars have attempted to address what, in particular, fosters a student's leadership development, specifically the ability to collaborate well in a team.

Lawson, Fallshaw, Papadopoulos, Taylor, and Zanko (2011) discuss how Australian university educators have begun to incorporate "professional learning" techniques into business curricula and stand-alone programs, which include developing "the skills, qualities and attributes that are required by industry" (p. 61). Moreover, professional learning focuses on learning related to a student's future career and engages the student directly with the industry to create "authentic learning environments" $(2011$, p. 62). This is congruent with the practice in the United States to incorporate a required internship or practicum in undergraduate leadership programs in order for students to gain real-life experiences in their future profession (Brungardt, Greenleaf, Brungardt, \& Arensdorf, 2006). Incorporating this component of learning also bridges the gap between leadership theory and application (Fincher \& Shalka, 2009).

When Lawson et al. (2011) introduced professional learning into the business curriculum at four Australian universities, the scholars identified eight types of professional learning experiences, noting the "types are not mutually exclusive" to creating industry-ready students (p. 64)--industry case study, industry simulation, industry practitioner delivery (i.e. professional specialized lectures), industry study tour (i.e. field trips and site visits), industry placement (i.e. internship or practicum), industry competition, industry project, and industry mentoring. In their seminal work on student leader development, Dugan and Komives (2007; 2010) indicated that, along with experiences and formal leadership programs, a mentoring relationship served as a large predictor for leadership efficacy. Priest and Donnelly (2014) explored mentoring relationships as they related to leadership development and found that "mentors showed how leadership ideas can be translated and used in real-life situations" (p. 112), giving students the confidence to utilize their learned collaborative skills.

McKim and Velez (2015) also identified a variety of learning experiences in which students had the potential to develop the plethora of skills needed for leadership in a professional environment. In this study, faculty participants unanimously agreed that students working on peer advisory boards enhanced a student's communication skills--a skill also further developed by being mentored by a faculty member at the institution. In addition, developing leadership skills and behaviors was associated with faculty mentoring, as well as assigning readings and having in-depth discussions.

There is a long list of behaviors associated with leadership education and development. The question remains, however, "how are these skills developed in college students?" Hartman, Allen, \& Miguel (2015) posit that leader development programs need to "clearly identify what 
area of development is being improved" (p. 454), and because employers are consistently looking for graduates who work well with others in a team environment, scholars must call attention to which components of leader development programs enhance such skills. The VALUE program utilizes multiple program components to challenge students to develop these collaborative skills and initiate change through to completion.

\section{Description of the Application}

The VALUE program is a year-long curricular and co-curricular experience for upper division students that represent the most promising and dedicated undergraduates in the Department of Leadership Studies. These students are challenged as part of their experience to go beyond a traditional experience in the classroom, and to embrace and dedicate themselves to deep service and individual development.

The curriculum of the VALUE program is designed around the undergraduate learning objectives of the department that houses the program. This program is explicitly designed with the intention that students will practice applying the theories and knowledge they have acquired in their university experience to real issues important to them. Students do not do hypothetical work, but are engaged directly in corporate, non-profit, and educational issues relevant to themselves, their organizations, and their communities.

Leadership is a collaborative process that occurs between and amongst people (Rost, 1991; Chrislip \& Larson, 1994), and it is critical that students have opportunities to develop these skills if they hope to be successful in doing leadership in communities and organizations upon graduation (Dugan \& Komives, 2010). The VALUE program has two major learning goals: 1) operations and 2) collaboration, which serve as the framework for the program objectives. From the perspective of operations, participants are expected to: effectively diagnose situations, understand the root causes and issues underlying problems and challenges, demonstrate initiative to both introduce change and persist to see change through to its completion, create and execute change plans around their specified track, and learn to make conscious choices about interventions throughout the change process. From a collaboration perspective, students are expected to: understand themselves and their role on the team, work successfully in a team environment, enhance their ability to network and communicate effectively, and demonstrate the ability to energize and effectively work across factions with multiple stakeholders.

Program Components. The program model (Figure 1) consists of five major components through which students progress in a quasi-cohort. Each particular program component is designed to meet the VALUE program learning objectives. 


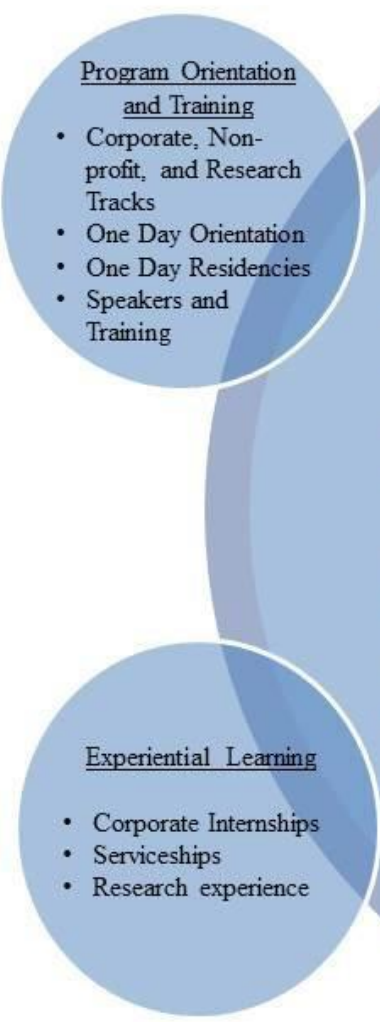

\section{Voss Advanced Leadership Undergraduate Experience}

Operations - To be successful in the leadership process, leaders must be able to move from ideas and concepts to action. They must be able to implement, execute and transform a vision into reality. Leaders and followers must simply "make it happen"

VALUE participants will:

- Effectively diagnose the situation, understanding the root causes and issues underlying problems and challenges

- Demonstrate initiative to both introduce change and persist to see change through to its completion

- Create and execute change plans around their specified track.

- Learn to make conscious choices about interventions throughout the change process

Collaboration - Participants in the leadership process must be able to work in a team environment to be successful. Leaders must be able to exercise collaborative skills where all players are involved in the decision making and implementation phases.

VALUE participants will:

- Understand themselves and their role on the team

- Work successfully in a team environment

- Enhance their ability to network and communicate effectively

- Demonstrate the ability to energize and effectively work across factions with multiple stakeholders
Mentoring and

Coaching

- Initial deep dialogue sessions

- One-on-One

throughout the year

Figure 1: VALUE Program Model

The first component is the program orientation and training. During this program, students explore their personal interests and develop a plan of study for their year related to one of three tracks: 1) Corporate, 2) Civic/Non-profit, or 3) Scholarship/Leadership Research. In addition to this orientation program, students also receive training and development from corporate, non-profit, and government leaders, as well as from Leadership Studies faculty, and have the opportunity to attend one professional conference identified by the program coordinator.

The second component is the mentoring component, which, according to the MultiInstitutional Study of Leadership, mentoring relationships directly impact a student's advances in leadership capacity (Campbell, Smith, Dugan, \& Komives, 2012). Once admitted to the VALUE program, students engage in an initial deep dialogue and mentoring sessions with a mentor related to their career and personal objectives. The mentor comes from outside the institution and department, thus giving the student another perspective from the faculty members. This mentor serves throughout the year working one-on-one with the student to develop and execute 
his/her project/plan(s). Training for the mentors was provided through a detailed handbook and subsequent discussions with the program director. Mentors and mentees were matched according to their track choice and expertise.

The next component is the Advanced Leadership Labs I and II. Courses in the form of a lab provide students with hands-on opportunities to hone skills. Advanced Leadership Lab I is taught during the fall semester, while Advanced Leadership Lab II is delivered during the spring semester. Content for the course focuses specifically on operations and collaboration skills, and the application of those skills through the project chosen around the students' track (corporate, civic/non-profit, or scholarship/leadership research). Self-assessment and reflection activities occur throughout this experience.

The fourth program component is the experiential learning component. The experiential learning component of the program serves as the core of the program as it creates both curricular and co-curricular learning opportunities throughout the year for students. Students' experiential learning is tied to their chosen track. Examples of experiential learning include, but are not limited to, corporate internships, serviceships (experiences similar to corporate internships but in the civic sector), and undergraduate research opportunities. Sample projects from the class involved, starting a photography business, working alongside the Court Appointed Special Advocate (CASA) organization, and conducting research on the prevalence of sexual assault occurrence and the perception of the campus climate at a university.

The final program component is the e-Portfolio. Students are assessed on their work through a competency based electronic portfolio (e-Portfolio). Each is expected to demonstrate competency across all learning goals and objectives of the VALUE program. To do so, students build an e-Portfolio of work over the year that documents their competency in the form of learning outcomes. Students present their final report and 'defend' their e-Portfolio through a formal presentation. This e-Portfolio was assessed by the faculty team and VALUE mentors.

\section{Discussion of Outcomes}

The VALUE program ended its inaugural year in May 2016, and a variety of assessments were used to measure the success of the program's various components. These assessments included a pre/post test of the student's self-perceived learning, a mentor evaluation, a mentee evaluation, focus groups, and rubrics used by the instructor to score the final paper/presentations and e-Portfolios.

One of the more prominent elements of the VALUE program included the mentoring relationships students had with an expert in their track area. The first year of creating these relationships proved to be a learning experience for all involved. As part of this journey, students were asked to reflect on each meeting with their mentors throughout the program via classroom assignments. Additionally, students and mentors were asked to evaluate their mentoring relationships by completing two evaluations. These assessments have shed light on the complexity of a mentoring relationship, but also revealed much about the students' and mentors' devotion to the relationship. At the end of the first term of the program's inaugural year, it was 
concluded that half of the mentor-mentee matches were successful, while the other half saw room for improvement. The evaluations included questions directed at the mentor's ability to challenge the student to think critically and offer feedback to the student, while students, or mentees, were evaluated on their ability to receive constructive feedback and develop problemsolving strategies. For sample questions taken from the evaluation, see Table 1.

Table 1.

Sample Questions from Mentor and Mentee Evaluations

\section{Sample Questions to Evaluate the Mentor Sample Questions to Evaluate the Mentee}

Critical Thinking: The mentor frequently takes the opportunity to ask reflective questions of the student. The mentor utilizes reflective questioning skills to invite the student to look at his or her practices with an eye for improvement.

Feedback: The mentor offers honest, supportive, and constructive feedback to help the student improve his/her competencies.

Challenge: The mentor challenges the student to take healthy, positive, and constructive risks.

Communication: The mentor maintains a continuous open line of communication with the student.
Critical Thinking: The student offers thoughtful responses to reflective questions asked by the mentor.

Feedback: The student respectfully accepts feedback and criticism in a professional manner.

Problem Solving: The student has demonstrated the ability to solve problems as they occur and he/she may even go beyond the help of the mentor to other resources.

Communication: The student maintains a continuous open line of communication with his/her mentor.

Matches were deemed successful when both the mentor and mentee reported positive results on the mentor and mentee evaluations. For example, one student stated, "I'm so grateful for the insight and overall guidance from her [my mentor]. I honestly do not think I would have gained as much from this experience without her."

Students with unsuccessful mentor relationships reported an inability to solidify the relationship within the time constraints of the first semester of the program, and needed more consistent meeting times, more meaningful conversations, or simply more communication between the mentor/mentee. For example, a student expressed, "My mentor and I were unable to make a strong connection due to a lack of time. Our schedules did not match and we were never able to truly connect on any topic other than surface material." Despite these challenges, the students recognized the importance of the mentor role. As one student stated, "This mentormentee relationship has been the most rewarding thing...." Another stated their mentor's role in 
overcoming insecurity, "More than anything, she has really helped me become much more confident in myself and in my major."

Mentors expressed similar thoughts about their mentor-mentee relationships, and it appeared that feelings about successful or unsuccessful relationships were mutual between mentors and mentees. One mentor stated of her successful relationship, "[My mentee] has done an excellent job communicating with me. She asks questions and seeks honest feedback. She is clearly eager to grow in knowledge and practice." While another, who had a less positive experience, stated, "In the end, I feel this was a good experience; however, some life events along the way caused some significant gaps in our time together." These mutual sentiments are congruent with the outcomes of the student-alumni mentoring program presented by Priest and Donley (2014).

The program and course pre/post assessments established for the VALUE program revealed the degree to which students self-reported whether they met the learning outcomes of the program. For example, when rating their level of knowledge (on a scale of one to four; four being very knowledgeable) at the beginning of the program on change interventions, organizational operations, and mentor relationships, the students rated an average of 2.33, 2.67, and 2.44 respectively. At the conclusion of the program, however, students rated their level of knowledge on each component as 3.00, 3.38, and 3.63 respectively. The comparison between the pre-assessment and post-assessment show that the students increased their level of knowledge on three topics covered throughout the program. More data will need to be collected over time to determine the significance of these score increases.

At the end of the year, the projects of the individual VALUE students were assessed by the faculty and mentors. This assessment took the form of a final paper and presentation along with the development of an e-Portfolio, and rubrics were used to evaluate the work of the students. These rubrics included grading criteria related to the students' ability to demonstrate the desired outcomes of the program. From an operations perspective, students were expected to demonstrate an ability to implement, execute, and transform their vision into reality. They were also expected to show how they exercised collaborative skills to build relationships through the project to continue and sustain their change. Finally, they were evaluated on their ability to reflect on their experiences and learn from their mistakes. While the papers and presentations varied by student, the students all demonstrated a satisfactory level of performance in these areas. The biggest opportunity for growth, based on the grading rubric, would have been the incorporation of additional artifacts into the e-Portfolios to demonstrate more of what the project included to viewers.

While the program's formal assessments have been valuable in measuring learning and program goals, perhaps the most beneficial information for program improvement has been the result of focus groups and individual discussions with the students in the program. One-on-one interviews with each student offered a greater depth of understanding of how each student experienced the program. Focus groups were conducted in an effort to address general concerns, and it is clear from those discussions that the students' mentoring relationship is key to the success of the program. 
Students praised the program during an exit focus group for its ability to offer real-world experiences and identify areas of improvement for the students as they enter their future careers. For example, all participants agreed that the program stretched them beyond their comfort zone, which resulted in learning more about their personal conflict management and conflict resolution styles. Communication skills were also developed through participation in the program. When asked about whether they enhanced their collaboration skills or ability to work within organizational operations as a result of the experience, all students stated yes, but to varying degrees dependent upon program track.

At the same time, students also expressed suggestions to increase the impact of the program for incoming scholars. Almost all students recommended that there should be specificity regarding the learning outcomes of the program, which has led the program facilitators to prepare more discussion of learning outcomes throughout the program's many activities or assignments within the course. Students who have struggled with developing a solid relationship with their mentor were not as positive about the VALUE experience; however, students that have garnered solid relationships with their mentor have expressed more positive experiences. Students who participated in the research track of the program all agreed that mentors for this particular track should be members of the local community, as each student had difficulty communicating research ideas in a virtual landscape.

\section{Reflections of Practitioner(s)}

Director Perspective. Overall, the implementation of the VALUE program has gone relatively well; however, I believe there is room for enhancement. Given much of my work with the program was in an administrative capacity, I relied primarily on student feedback and assessment data to gauge the effectiveness of the program. Students have shared that they were not given enough information or examples of what each track in the program could look like; therefore, we are exploring a variety of options to give students more information about each track before their selection in the fall. In addition, students expressed that meeting their mentors earlier could have greatly improved their relationship. As a result, we anticipate beginning the fall program at the start of the semester and matching students with their mentors as early as September.

Matching professionals with student scholars was, perhaps, the most critical task to ensuring the success of the program. It was imperative to understand the personalities of both the students and potential mentors in attempt to create the "perfect" match. At the same time, it was important for students to have a self-reflective learning experience through each component of the program; therefore, if the match wasn't perfect, there was a lesson in leadership to be learned. This is not to say that we matched students and mentors without considering personalities and/or field interests; however, should the mentoring relationship begin to decline, my first reaction was not to re-match, but rather problem work through and solve the conflict with the student. 
In addition, assisting students in selecting their VALUE projects took more time than I initially perceived, as recruiting organizations open to the opportunity proved to be difficult. Knowledge of the new program had not spread widely among the community, so I was obligated to contact organizations our department had worked for in the past on community projects. On the other hand, students were not as heavily involved in the process as I originally intended; therefore, I plan to shift a majority of the responsibility in selecting organizations for VALUE projects back to the student in an attempt to provide them more empowerment. Not only will this alleviate some work on my end, it will allow the students to step outside their comfort zone and approach organizations, personally, with their vision for a project.

Lastly, students offered mixed responses in regard to the leadership conference they attended in the spring semester. Some students found the information beneficial, while a majority felt they should have attended a conference with more direct applicability to their VALUE projects; therefore, I am exploring conference options that are more experiential or problembased, rather than on developing knowledge capacity.

Overall, the team environment between faculty and staff in the program, and the program's donor, proved to be successful, as many of our challenges were quickly overcome through collaboration among all entities.

Instructor Perspective. The VALUE program included two classes that were one semester each (Advanced Lab I and Advanced Lab II). The approach I took with these classes was different than other classes I teach for a number of reasons. First, all the students in the class had completed the Leadership Studies certificate. Having this shared foundation allowed me the freedom to focus on more complex theories, concepts, and behaviors. A small class size (nine students) allowed me to spend more time and focus more intently on the individual students in the classes. Additionally, the students were selected from a pool of applicants, which seemed to intrinsically motivate them to perform well.

The approach I took to instructing the classes best aligns with the idea of Problem Based Learning (PBL). The PBL approach is one in which the students are encouraged to take responsibility for their own education (Coombs \& Elden, 2004). In this type of setting the role of the instructor shifts from the traditional lecturer to facilitator and guide. This was challenging for me because it is not something I have tried before, and I was honest with the students upfront about that fact. Throughout the class, I attempted a variety of assignments ranging from studentled discussions and peer consultations to case-in-point teaching and strategic planning. The peer consultations took place primarily in the first semester and included placing the students into teams with one student presenting their project or project idea and the other students in the group serving as consultants. There was a structured process to follow and the students really felt that this was valuable in thinking through their projects. The case in point approach focused on finding an individual in the class to use as a case study based on what they were experiencing in their project. This was used primarily in the second semester when the projects were underway and proved to be challenging to do well. The work at the end of the semester was synthesized in an e-Portfolio. 
In reflecting on the first year and the focus group that was held with the students at the end of the second semester, the most meaningful assignments were those that encouraged the students to think critically about themselves and/or their real-time projects, as well as the projects of their peers (e.g. peer consultations). It was in these moments of reflection that the elements of operations and collaboration seemed to combine and spark insights into meaningful change. This was especially true in the second semester when the students' projects were in progress. Looking back over the year, I believe it would have been beneficial to include more structured progress checks throughout the year. While the students were motivated and the class was designed to afford the students a certain level of autonomy, the implementation of policies to hold them accountable to a high level of continued engagement would have benefited many of the students. One step to accomplishing this might be through further implementation of grading rubrics. However, the grading rubrics need to be revised based on lessons learned throughout the year and normed with the help of other faculty to improve their usefulness.

\section{Recommendations/Conclusions}

The Voss Advanced Leadership Undergraduate Experience (VALUE) has been a unique opportunity for students, faculty, and mentors. As the program continues to expand and grow, the incorporation of both international and online leadership students will be a high priority. Beginning small with the on-campus population was intentional for the program's inaugural year; however, expanding the program's reach to include all modalities is critical. The use of the departmental advisory board was also critical in the creation of the VALUE program, resulting in multiple mentor volunteers, as well as project ideas for the students.

While program and course assessments were created along with the design of VALUE, which has led to well thought out program and student learning outcomes evaluations, the program has also led its faculty to collaborative research opportunities with other leadership programs and scholars across the country. A longitudinal assessment team has been created to research the long-term impact of the VALUE program as students matriculate into the workforce. This research will focus on priorities one (Explore the Capacity and Competency Development Process for Leadership Education) and two (Assess Viable Programmatic Assessment Resources) from the National Leadership Education Research Agenda (Andenoro et al., 2013).

In conclusion, the VALUE program can serve as a comprehensive framework for leadership programs across the country that seek to utilize innovative approaches to teaching and learning through high-impact pedagogy, use of alumni mentors, and robust student learning and program assessment. 


\section{References}

Andenoro, A. C., Allen, S. J., Haber Curran, P., Jenkins, D. M., Sowcik, M., Dugan, J. P., \& Osteen, L. (2013). National leadership education research agenda 2013-2018: Providing strategic direction for the field of leadership education. Retrieved from Association of Leadership Educators website: http://leadershipeducators.org/ResearchAgenda.

Astin, A. W. \& Astin, H. S. (2000). Leadership reconsidered: Engaging higher education in social change. Battle Creek, MI: W. K. Kellogg Foundation.

Brungardt, C., Greenleaf, J., Brungardt C., \& Arensdorf, J. (2006). Majoring in leadership: A review of undergraduate leadership degree programs. Journal of Leadership Education, $5(1), 4-25$.

Campbell, C. M., Smith, M., Dugan, J. P., \& Komives, S. R. (2012). Mentors and college student leadership outcomes: The importance of position and process. Review of Higher Education, 35(4), 595-625.

Chrislip, D., \& Larson, C. 1994. Collaborative leadership: How citizens and civic leaders can make a difference. San Francisco: Jossey-Bass.

Coombs, G. \& Elden, M. (2004). Introduction to the special issue: Problem-based learning as social inquiry-PBL and management education. Journal of Management Education, 28(5), 523-535.

Dugan, J. \& Komives, S.P. (2007). Developing leadership capacity in college students: Findings from a national study. A Report from the Multi-Institutional Study of Leadership. College Park, MD: National Clearinghouse for Leadership Programs.

Dugan, J. P. \& Komives, S. P. (2010). Influences on college students' capacities for socially responsible leadership. Journal of College Student Development, 51(5), 525-549. doi: 10.1353/csd.2010.0009

Fincher, J. \& Shalka, T. R. (2009). Co-curricular leadership education: Considering critical questions. Journal of Leadership Education, 8(1), 228-237.

Franz, J. M. (2008). A pedagogical model of higher education/industry engagement for 
enhancing employability and professional practice. In Proceedings of Work Integrated Learning (WIL): transforming futures, practice... pedagogy... partnerships, WIL Manly, Sydney, pp. 164-169.

Hartman, N. S., Allen, S. J., \& Miguel, R. F. (2015). An exploration of teaching methods used to develop leaders: Leadership educators' perceptions. Leadership \& Organization Development Journal, 36(5), 454-472.

Jackson, D., Sibson, R., \& Riebe, L. (2014). Undergraduate perceptions of the development of team-working skills. Education and Training, 56(1), 7-20.

Lawson, R., Fallshaw, E., Papadopoulos, T., Taylor, T., \& Zanko, M. (2011). Professional learning in the business curriculum: Engaging industry, academics and students. Asian Social Science, 7(4), 61-68.

McKim, A. J. \& Velez, J. J. (2015). Exploring leadership skill development and the related curricular experiences in a year-long leadership development program. Annual Conference Proceedings. Paper presented at The Association for Leadership Educators 25th Anniversary Conference, Washington, D.C., 12-15 July (pp. 634-646).

National Association for Colleges and Employers [NACE]. (2014). The skills/qualities employers want in new college graduate hires [Press release]. Retrieved from https://www.naceweb.org/about-us/press/class-2015-skills-qualities-employers-want.aspx

Priest, K. \& Donley, S. (2014). Developing leadership for life: Outcomes from a collegiate student-alumni mentoring program. Journal of Leadership Education, 13(3), 107-117.

Rost, J.C. (1991). Leadership for the twenty-first century. New York: Praeger.

Wagner, W. (2006). The social change model of leadership: A brief overview. Concepts \& Connections, 15(1), 9.

\section{Author Biographies}

Dr. Justin Greenleaf is an assistant professor in the Department of Leadership Studies at Fort Hays State University. Dr. Greenleaf teaches primarily undergraduate classes related to leadership theory and behavior. Dr. Greenleaf's areas of expertise are related to community psychology and leadership in the context of community. His research interests focus on the practical application of leadership. He can be reached at jpgreenleaf@ fhsu.edu. 
Kaley Klaus is the Director of Student Leadership Development \& Assessment in the Department of Leadership Studies and the Center for Civic Leadership at Fort Hays State University. Her areas of expertise include program development, assessment, and evaluation, and leadership theory. Kaley holds a Master of Professional Studies degree in Organizational Leadership. She can be reached at krklaus@fhsu.edu.

Dr. Jill Arensdorf is an associate professor and chair of the Department of Leadership Studies at Fort Hays State University (FHSU). Dr. Arensdorf has been on the faculty team at FHSU for fourteen years, teaching courses in leadership theory and leadership behaviors. Dr. Arensdorf's research interests include civic engagement and leadership, leadership behavior and skill development, and the transfer of learning. She can be reached at irarensdorf@ fhsu.edu. 